\title{
Comparison of six pediatric cardiopulmonary bypass pumps during pulsatile and nonpulsatile perfusion
}

\author{
Akif Ündar, PhD, a,b,c Harald C. Eichstaedt, MD, ${ }^{c}$ Takafumi Masai, MD, ${ }^{c}$ Shuang-Qiang Yang, MD, ${ }^{c}$ \\ Joyce E. Bigley, CCP, Mary Claire McGarry, CCP, Maryann Mueller, CCP, William K. Vaughn, PhD, ${ }^{\mathrm{d}}$ and \\ Charles D. Fraser, Jr, MD, a,c,e Houston, Tex
}

S everal investigators have shown that pulsatile perfusion improves vital-organ recovery after hypothermic cardiopulmonary bypass (CPB) with or without deep hypothermic circulatory arrest (DHCA). ${ }^{1-4}$ Nevertheless, pulsatile perfusion remains controversial, and only a few pediatric centers use it routinely. ${ }^{5}$ The main reason for this controversy is lack of quantification of pulsatile and nonpulsatile pressure-flow waveforms. We propose to end the controversy by quantifying pulsatile flow with Shepard's energy equivalent pressure (EEP) formula, which accounts for both arterial-pressure and pump-flow waveforms and not pressure waveforms alone. ${ }^{6-8}$ Generation of pulsatile flow depends on an energy gradient rather than on a pressure gradient. The following formula is used to define the EEP:

$$
\mathrm{EEP}=\left(\int \mathrm{fpdt}\right) /\left(\int \mathrm{fdt}\right)
$$

where $\mathrm{f}$ is the pump flow rate (in milliliters per second), $\mathrm{p}$ is the arterial pressure, and the time integrals are over one pulse cycle. The EEP, which is expressed in millimeters of mercury, is the ratio of the areas beneath the hemodynamic power curve ( (ffpdt) and the pump flow-rate curve ( $\int \mathrm{fdt}$ ) at the end of the flow and pressure cycles.

To determine whether the pulsatile or nonpulsatile perfusion mode yields the greatest hemodynamic energy during $\mathrm{CPB}$, we evaluated 6 pediatric pumps in terms of the EEP before and after DHCA in a neonatal piglet model.

\section{Experimental Design}

Thirty-nine piglets (average weight, $3 \mathrm{~kg}$ ) were subjected to $\mathrm{CPB}$ with one of the following: a hydraulically driven physiologic pul-

\footnotetext{
From the Congenital Heart Surgery Service, ${ }^{\mathrm{a}}$ Texas Children's Hospital; Division of Congenital Heart Surgery, Michael E. DeBakey Department of Surgery, ${ }^{\text {b }}$ Baylor College of Medicine; Cullen Cardiovascular Surgical Research Laboratories, ${ }^{\mathrm{c}}$ Texas Heart Institute; Department of Biostatistics and Epidemiology, ${ }^{\mathrm{d}}$ Texas Heart Institute; and Department of Pediatrics, ${ }^{\mathrm{e}}$ Baylor College of Medicine, Houston, Tex.

This study was supported in part by a grant from the American Heart Association, Texas Affiliate, to Dr Akif Ündar (grant 98BG197).

Received for publication Feb 5, 2001; accepted for publication Feb 8, 2001.

Address for reprints: Akif Ündar, PhD, Texas Children's Hospital/Baylor College of Medicine, Congenital Heart Surgery Service, 6621 Fannin St, MC 1-2285, Houston, TX 77030-2399 (E-mail: aundar@bcm.tmc.edu).

J Thorac Cardiovasc Surg 2001;122:827-9

Copyright $(2001$ by The American Association for Thoracic Surgery

0022-5223/2001 $\$ 35.00+0 \quad \mathbf{1 2 / 5 4} / \mathbf{1 1 4 9 3 1}$

doi:10.1067/mtc.2001.114931
}

satile pump ( $\mathrm{n}=7$; Medical Engineering Consultants, Bishop, Calif), a Jostra HL-20 pulsatile roller pump ( $n=6$; Jostra USA, Austin, Tex), a Stöckert SIII pulsatile roller pump ( $n=6$; Stöckert, Munich, Germany), a Stöckert SIII mast-mounted pulsatile roller pump with a miniature roller head $(n=7)$, a Stöckert SIII mastmounted nonpulsatile roller pump with a miniature roller head (n $=6$ ), or a Stöckert CAPS nonpulsatile roller pump $(n=7)$. All animals received humane care, as described in the "Guide for the Care and Use of Laboratory Animals" of the National Research Council (National Academy Press, revised 1996).

Each piglet was premedicated with intramuscular ketamine hydrochloride $(20 \mathrm{mg} / \mathrm{kg})$ and acepromazine maleate $(1 \mathrm{mg} / \mathrm{kg})$. Once an intravenous line was established, a 3-mm endotracheal tube was inserted for mechanical ventilation. Intravenous boluses of fentanyl citrate $(100 \mu \mathrm{g} / \mathrm{kg})$ and pancuronium bromide $(0.3$ $\mathrm{mg} / \mathrm{kg}$ ) were then given. After a median sternotomy was performed, the ascending aorta and the right atrium were cannulated with a $10 \mathrm{~F}$ aortic cannula (DLP, Inc, Grand Rapids, Mich) and a $21 \mathrm{~F}$ single-stage venous cannula (Polystan A/S, Varlose, Denmark), respectively.

The extracorporeal circuit was primed with heparinized fresh blood and lactated Ringer's solution. The priming volume for the whole circuit was approximately $600 \mathrm{~mL}$. During CPB, the hematocrit level was maintained at $20 \%$. In all the experiments, a hollow-fiber membrane oxygenator (Capiox SX10; Terumo Corp, Tokyo, Japan) and a pediatric arterial filter (Terumo Corp) were used. During pulsatile CPB, the pump rate was maintained at 150 beats $/ \mathrm{min}$, and the stroke volume was maintained at $1 \mathrm{~mL} / \mathrm{kg}$. Pump flow was maintained at $150 \mathrm{~mL} \cdot \mathrm{kg}^{-1} \cdot \mathrm{min}^{-1}$ in all the groups. An ultrasonic flow probe (T109; Transonic Systems, Inc, Ithaca, NY) was placed in the circuit beyond the membrane oxygenator to measure blood flow. During $\mathrm{CPB}$, the mean arterial pressure (MAP) was maintained at approximately $45 \mathrm{~mm} \mathrm{Hg}$ by adding isoflurane through the oxygenator gas-inflow conduit. At the end of the experiment, the animal was killed with an intravenous bolus of pentobarbital sodium and phenytoin sodium (Beuthanasia-D; $0.22 \mathrm{mg} / \mathrm{kg}$ ).

Once CPB was begun, each animal underwent 15 minutes of normothermic CPB, 25 minutes of hypothermia, 60 minutes of deep hypothermic circulatory arrest, 10 minutes of cold reperfusion, and 40 minutes of rewarming. After the ascending aorta was crossclamped at $18^{\circ} \mathrm{C}$, a $40-\mathrm{mL}$ dose of crystalloid cardioplegic (modified Kirklin) solution was manually administered into the aorta. During cooling and rewarming, alpha-stat acid-base management was used. In all experiments phenoxybenzamine (1 $\mathrm{mg} / \mathrm{kg}$ ), a potent vasodilator and $\alpha$-adrenergic blocker, was used 5 minutes before the initiation of CPB. 
TABLE 1. Femoral artery pressure: percentage of change from MAP to EEP

\begin{tabular}{|c|c|c|c|}
\hline Pump & Normothermic CPB (mm Hg) & Hypothermic CPB (mm Hg) & Postrewarming period (mm $\mathrm{Hg})$ \\
\hline & $12.9 \pm 3.2(50.4 \pm 4.9$ to $56.9 \pm 5.2) \dagger \ddagger$ & $15.3 \pm 4.0(45.8 \pm 8$ to $52.6 \pm 8.8) \dagger \ddagger$ & $16.3 \pm 4.5(48.4 \pm 18.3$ to $56.2 \pm 20.8) \dagger \ddagger$ \\
\hline pulsatile roller & $5.3 \pm 1.2(39.6 \pm 6.9 \text { to } 41.6 \pm 6.8)^{*}$ & $4.8 \pm 0.8(44.7 \pm 6.4 \text { to } 46.8 \pm 6.3)^{*}$ & \\
\hline I pulsatile roller & $3.7 \pm 1.2(43.5 \pm 10.7 \text { to } 45 \pm 10.8)^{*}$ & $4.5 \pm 0.5(38.2 \pm 6.7 \text { to } 39.9 \pm 6.8)^{*}$ & 11.8 to $51.1 \pm 12.4)^{*}$ \\
\hline $\begin{array}{l}\text { Stöckert SIII mast-mounted } \\
\text { pulsatile roller }\end{array}$ & $-0.3 \pm 1.6(45.2 \pm 8.7 \text { to } 45.2 \pm 9.1)^{*}+\ddagger$ & $-0.2 \pm 1.4(43.9 \pm 7.4 \text { to } 43.7 \pm 7.1)^{*} † \ddagger$ & $-1.8 \pm 1.7(51.6 \pm 12.4 \text { to } 50.5 \pm 11.5)^{*} \dagger \ddagger$ \\
\hline $\begin{array}{l}\text { Stöckert SIII mast-mounted } \\
\text { nonpulsatile roller }\end{array}$ & $-0.2 \pm 1.8(43 \pm 4.8 \text { to } 43 \pm 5.0)^{*} † \ddagger$ & $-0.4 \pm 0.7(46.1 \pm 3.6 \text { to } 45.9 \pm 3.6)^{*} † \ddagger$ & $-0.9 \pm 2.2(51.9 \pm 9.2 \text { to } 51.4 \pm 9.1)^{*} † \ddagger$ \\
\hline $\begin{array}{l}\text { Stöckert CAPS } \\
\text { nonpulsatile roller }\end{array}$ & $0.7 \pm 0.5(49 \pm 5.4 \text { to } 49.4 \pm 5.3)^{*} † \ddagger$ & $0.9 \pm 0.9(43.9 \pm 12.1 \text { to } 44.2 \pm 12.0)^{*} \dagger \ddagger$ & $0.7 \pm 0.5(47.4 \pm 14 \text { to } 47.8 \pm 14.1)^{*} \dagger \ddagger$ \\
\hline
\end{tabular}

Values are given as means \pm standard deviation.

${ }^{*} P<.0001$ versus the Physiologic pulsatile pump.

$\dagger P<.001$ versus the Jostra HL-20 pulsatile roller pump.

$\ddagger P<.01$ versus the Stöckert SIII pulsatile roller pump.

TABLE 2. Preaortic cannula ECCP: Percentage of change from ECCP to EEP

\begin{tabular}{|c|c|c|c|}
\hline Pump & Normothermic CPB (mm Hg) & Hypothermic CPB (mm Hg) & Postrewarming period (mm Hg) \\
\hline Physiologic pulsatile & $45.9 \pm 13.1(70.4 \pm 6.9$ to $102.6 \pm 12.4) \dagger \ddagger$ & $46.4 \pm 11.3(65.6 \pm 13.7$ to $95.7 \pm 19.3) \dagger \ddagger$ & $52.0 \pm 10.0(74.5 \pm 17.3$ to $112.1 \pm 21.0) \dagger \ddagger$ \\
\hline $\begin{array}{l}\text { Jostra HL-20 pulsatile } \\
\text { roller }\end{array}$ & $14.5 \pm 3.9(59.5 \pm 11.9 \text { to } 67.9 \pm 12.5)^{*}$ & $12.2 \pm 2.6(66.6 \pm 6.9 \text { to } 74.6 \pm 6.6)^{*}$ & $14.8 \pm 2.7(63.1 \pm 9.4 \text { to } 72.6 \pm 11.8)^{*}$ \\
\hline $\begin{array}{l}\text { Stöckert SIII pulsatile } \\
\text { roller }\end{array}$ & $9.2 \pm 1.3(64.1 \pm 19.2 \text { to } 69.9 \pm 20.4)^{*}$ & $11.2 \pm 1.8(54.9 \pm 7.8 \text { to } 61.0 \pm 8.5)^{*}$ & $9.0 \pm 2.8(70.1 \pm 15.5 \text { to } 76.1 \pm 15.5)^{*}$ \\
\hline $\begin{array}{l}\text { Stöckert SIII } \\
\text { mast-mounted } \\
\text { pulsatile roller }\end{array}$ & $1.2 \pm 3.0(65.8 \pm 14.1 \text { to } 66.6 \pm 14.6)^{*} \dagger \ddagger$ & $2.6 \pm 2.2(68.4 \pm 19.1 \text { to } 69.9 \pm 18.4)^{*} † \ddagger$ & $-0.5 \pm 1.4(69.9 \pm 19 \text { to } 69.5 \pm 18.5)^{*} \dagger \ddagger$ \\
\hline $\begin{array}{l}\text { Stöckert SIII } \\
\text { mast-mounted } \\
\text { nonpulsatile roller }\end{array}$ & $1.3 \pm 1.8(59.1 \pm 5.7 \text { to } 59.9 \pm 6.6)^{*} † \ddagger$ & $1 \pm 0.2(70.5 \pm 6.6 \text { to } 71.2 \pm 6.6)^{*} † \ddagger$ & $-0.7 \pm 1.3(73.4 \pm 13.6 \text { to } 72.9 \pm 13.7)^{*} † \ddagger$ \\
\hline $\begin{array}{l}\text { Stöckert CAPS } \\
\text { nonpulsatile roller }\end{array}$ & $1.9 \pm 0.4(68.2 \pm 13.8 \text { to } 69.5 \pm 13.8)^{*} \dagger \ddagger$ & $1.7 \pm 0.8(59.4 \pm 8.7 \text { to } 60.3 \pm 8.5)^{*} † \ddagger$ & $1.9 \pm 0.7(73.9 \pm 10.1 \text { to } 75.2 \pm 10.1)^{*} \dagger \ddagger$ \\
\hline
\end{tabular}

Values are given as means \pm standard deviation.

${ }^{*} P<.0001$ versus the Physiologic pulsatile pump.

$\dagger P<.001$ versus the Jostra HL-20 pulsatile roller pump.

$\ddagger P<.01$ versus the Stöckert SIII pulsatile roller pump.

Waveforms of the femoral artery pressure (MAP), precannula extracorporeal circuit pressure (ECCP), and pump flow were collected during 3 experimental stages: (1) normothermic CPB (after 15 minutes on pump at $36^{\circ} \mathrm{C}$ ); (2) deep hypothermic CPB (immediately before DHCA at $18^{\circ} \mathrm{C}$ ); and (3) the postrewarming period (after 60 minutes of DHCA, 10 minutes of cold reperfusion, and 40 minutes of rewarming).

Analysis of variance with repeated measures was used for statistical analysis among the 6 groups. All results were expressed as means \pm standard deviation.

\section{Results}

Tables 1 and 2 summarize the results. The physiologic pulsatile pump produced the greatest hemodynamic energy. Compared with all the other pumps except the physiologic pulsatile model, the Jostra and SIII pulsatile roller pumps produced a significantly higher average increase in hemodynamic energy (from MAP to EEP and from ECCP to EEP). This extra energy produced by pulsatile pumps may maintain capillary patency and increase the flow of lymph fluid in the tissues by generating oscillatory movements at the cellular level. ${ }^{9}$ During deep hypothermic CPB and after rewarming, the results did not differ from those observed during normothermic CPB. The SIII mast-mounted pulsatile roller pump failed to generate higher hemodynamic energy than the nonpulsatile pumps because it had a miniature roller head. None of the nonpulsatile roller pumps produced extra energy. There were no differences between the MAP-EEP or the ECCP-EEP during nonpulsatile perfusion.

The physiologic pulsatile pump used in this study is hydraulically driven and is unique in that it has 2 pump chambers. The first chamber is placed between the venous reservoir and the membrane oxygenator, and the second chamber is positioned after the membrane oxygenator. Therefore, in this set-up the oxygenator does not affect the quality of the pulsatility. A detailed description of this pump is presented elsewhere. ${ }^{10}$ All the other pumps used in this study, except the physiologic pulsatile pump, are approved by the Food and Drug Administration for clinical use. The Capiox hollow-fiber membrane oxygenator and the DLP aortic cannula were chosen specifically for this study because of their previous excellent performance with pulsatile flow pumps. ${ }^{11,12}$ 


\section{Conclusion}

Most of the pediatric pulsatile pumps (hydraulically driven or pulsatile roller) that we tested, but not all of them, generated significantly higher hemodynamic energy than did the conventional, nonpulsatile pumps. On the basis of these results, further studies are warranted to confirm that the extra energy produced by pulsatile flow improves vital-organ function after CPB. For direct comparison of the different perfusion modes, the EEP formula must be used to quantify pulsatile and nonpulsatile pressure-flow waveforms.

\section{References}

1. Ündar A, Masai T, Yang SQ, Goddard-Finegold J, Frazier OH, Fraser CD. Effects of perfusion mode on regional and global organ blood flow in a neonatal piglet model. Ann Thorac Surg. 1999;68:1336-43.

2. Ündar A. Design and performance of physiologic pulsatile flow cardiopulmonary bypass systems for neonates and infants [thesis]. Autin (TX): The University of Texas at Austin; 1996.

3. Williams GD, Seifen AB, Lawson NW, et al. Pulsatile perfusion versus conventional high-flow nonpulsatile perfusion for rapid core cooling and rewarming of infants for circulatory arrest in cardiac operation. J Thorac Cardiovasc Surg. 1979;78:667-77.
4. Yasui H, Yonenaga K, Kado H. Open-heart surgery in infants using pulsatile high-flow cardiopulmonary bypass. J Cardiovasc Surg. 1989; 30:661-8.

5. Groom RC, Hill AG, Kurusz M, et al. Pediatric perfusion practice in North America: an update. Perfusion. 1995;10:393-401.

6. Shepard RB, Simpson DC, Sharp JF. Energy equivalent pressure. Arch Surg. 1966;93:730-40.

7. Ündar A, Frazier OH, Fraser CD. Defining pulsatile perfusion: quantification in terms of energy equivalent pressure. Artif Organs. 1999; 23:712-6.

8. Ündar A, Masai T, Frazier OH, Fraser CD. Pulsatile and nonpulsatile flows can be quantified in terms of energy equivalent pressure during cardiopulmonary bypass for direct comparisons. ASAIO J. 1999;45:610-4.

9. Taylor KM. Pulsatile perfusion. In: Taylor KM, editor. Cardiopulmonary bypass. Baltimore: Williams \& Wilkins; 1986. p. 85-114.

10. Ündar A, Masai T, Inman R, et al. Evaluation of a physiologic pulsatile pump system for neonate-infant cardiopulmonary bypass support. ASAIO J. 1999;45:53-8.

11. Ündar A, Lodge AJ, Daggett CW, Runge TM, Ungerleider RM, Calhoon JH. The type of aortic cannula and membrane oxygenator affect the pulsatile waveform morphology produced by a neonateinfant cardiopulmonary bypass system in vivo. Artif Organs. 1998; 22:681-6.

12. Ündar A, Koenig KM, Frazier OH, Fraser CD. Impact of membrane oxygenators on pulsatile versus nonpulsatile perfusion in a neonatal model. Perfusion. 2000;15:111-20. 